\title{
Kelly's Strategy Analysis in Optimizing Investment Portfolios in Foreign Exchange
}

\author{
Evi Sulviah Ningsih, Sukono, Endang Rusyaman, Jajang Badruzaman, Puspa Liza Binti Ghozali
}

\begin{abstract}
Investments in financial markets not only pay attention to promising profits, but also need to consider the risks that follow. Risks can be minimized by establishing an investment portfolio. This research was conducted with the aim of analyzing optimal portfolios on foreign exchange investments, so that investments made provide maximum returns at certain risks, or minimal risk on certain returns. The data analyzed in this study are foreign exchange traded at Bank Indonesia. Data analysis is carried out quantitatively using the Kelly Strategy model. The steps: (i) Calculation of individual foreign exchange returns, (ii) Determine the average value of individual foreign exchange returns, (iii) Determine the optimal portfolio using the Kelly strategy approach, and (iv) Determine portfolio returns and risks. Based on the results of the analysis obtained the allocation of weights that provide returns and risks to the optimal portfolio. A $95 \%$ USD currency is an optimal portfolio of the five currencies used. So that it can be used as a consideration for investors, in making investment decisions in the foreign exchange being analyzed.
\end{abstract}

Index Terms: Investment, financial market, Kelly strategy approach.

\section{INTRODUCTION}

For survival, the community must have more income to meet their daily and future needs. Investment can be used as a solution for people to earn more income. One investment tool that is quite promising is foreign exchange. Exchange rate is the price of one currency expressed in terms of another currency [12]. In any investment, an analysis of the expected return and the assumed risk constitutes a fundamental step. Investing in financial assets is no exception. Since the portfolio selection theory was proposed by Markowitz in 1952, this methodology has become the benchmark in portfolio management [8], investors can diversify or allocate investment instruments into portfolios, since many studies indicate that greater profits can be made by diversifying internationally [1]. According to Markowitz's Modern Portfolio Theory (MPT), efficient portfolios are those that

Revised Manuscript Received on April 25, 2019.

Evi Sulviah Ningsih, Master Program in Mathematics, Faculty of Mathematics and Natural Sciences, Universitas Padjadjaran, Indonesia.

Sukono, Department of Mathematics, Faculty of Mathematics and Natural Sciences, Universitas Padjadjaran, Indonesia

Endang Rusyaman, Department of Mathematics, Faculty of Mathematics and Natural Sciences, Universitas Padjadjaran, Indonesia

Jajang Badruzaman, Department of Accounting, Faculty of Economic, Siliwangi University, Indonesia

Puspa Liza Binti Ghozali, Faculty of Informatic and Computing, Universiti Sultan Zainal Abidin, Indonesia. generate the highest expected return given a level of risk, or those with the lowest risk, given a level of return [2].

Previous research has been widely discussed including the ultimate goal of each investor is to obtain a consistent profit. Simsek [20] assumes that any financial innovation in portfolio risk tends to lead to speculation rather than risk sharing because of the motives of investors in the market [21]. Then the Optimal $f$ and the Kelly Criterion, the Kelly Criteria cannot be identified with the optimal allocation for "fractions" to the trading situation except in the case case, while Optimal f can be solved with the optimal fraction to obtain risk in all cases. This problem can affect an investor who wants to implement Optimal in his investment. One of the main obstacles for this case is that geometric growth in investment with Optimal $\mathrm{f}$ is a lack of knowledge about where the optimal conditions will be in the future [4]. The handbook of Asset and Lability Management which raises the problem of risk-adjusted returns. If profit opportunities are obtained, investors must determine how much capital they will invest [22]. Therefore, as long as the profit opportunity is uncertain, long-term investments must further limit the investment capital they have to prevent significant risks and overbetting [5].

Mean-Variance approach to portfolio optimization, where return is defined using changes in average asset prices over time, oversimplifies the problem and ignores the movement of large liabilities in various securities values in the portfolio. A better reflection is to determine the probability distribution of price changes for each asset in the portfolio and redefine the return function in this case the probability [23]. The relationship between the Markowitz portfolio and Kelly's optimal, where Kelly's strategy optimization for simplifying asset prices is to get the optimal portfolio weight by maximizing the expected profit. Kelly's optimal portfolio does not need to include all available assets [14].

In this paper, the role of Kelly's Strategy is analyzed in the allocation of investment portfolio weights to determine foreign exchange which can provide maximum benefits with certain risks. The objects that will be analyzed are all foreign currencies traded in the Foreign Exchange market in

Indonesia, including USD (United States Dollar), JYP (Japanese Yen), GBP (British Pound), CHF (Swiss Franc), and CNY ( Chinese Yuan). 


\section{BASIC CONCEPT}

Investment is an asset that is bought with the idea that assets will provide benefits in the future or later will be sold at a higher price for profit. This means that the higher the weight of an asset, the higher expected expected performance [11].

Currencies have been historically viewed as a medium of exchange, store of value and unit of account. The fixed exchange rate regime for exchange rates does not fluctuate under normal circumstances. However, when the era of flexible exchange rates started, foreign exchange rates experienced many upward and downward movements, depending on the dictates of market forces. The determination of exchange rates by supply and demand has also opened up an opportunity for investors. In other words, currency assets can be considered as financial assets, similar to stocks and bond bonds [17]. Foreign exchange intervention is the practice of monetary authorities buying and selling currency in the foreign exchange market to influence exchange rates [15]. Foreign portfolio inflows are expected to finance the difference between domestic savings and investment, without increasing the foreign currency debt of the country. Portfolio flows are considered as 'hot capital' and move from one country to another with searching the highest returns and better market conditions [9].

The investment portfolio management process consists of an integrated set of steps to create an appropriate mixture of assets. Since it is highly depending on characteristics of the investor, it is possible to stress three main steps: planning, execution and feedback. The most crucial part of portfolio management is the execution step during which a suitable portfolio is built. The procedure takes into account asset allocation, security analysis and investor requirements [4].

An efficient investment strategy is obtained by maximizing the level of investment growth in the long run. In the case of fixed assets, this is equivalent to maximizing the logarithm of wealth $w_{1}$ after one time step. Therefore, the key quantity in building

$$
\max _{w}=E\left[\ln w^{\prime}\right]
$$

know as the average wealth exponential growth rate where $w=w_{0}+E\left[R_{p}\right]$. Maximization $\max _{w}$ with respect to $w$ without limitation is obtained by solving $\frac{\max _{w}}{\max _{w_{1}}}=0,(k=1,2, \Lambda, n)$ where $E\left[R_{p}\right]=\sum_{i=1}^{n} w_{i} \mu_{i}$

with consequence

$$
E\left[\frac{\mu_{i}}{w_{0}}+\sum_{i=1}^{n} w_{i} \mu_{i}\right]=0 \quad k=0,1, \Lambda, n
$$

Where $\mu_{i}=\in(-1, \infty) \quad$ constraint $\sum_{i=1}^{n} w_{i}>1$ or $w_{i}<0$ will make $\max _{w}$.

\section{METHODOLOGY}

\section{A. Return kurs}

Return can be referred to as a measure of the total profit or loss of an investment over a specified period of time with respect to both changes in market value and cash distribution. Usually, profit is said to be a percentage [18].

Return $R_{t}$ of an asset at time ${ }^{t}$ (without dividends) is defined as $P_{t}$, as the exchange rate of the asset price at time $t$, and $P_{t-1}$ is the price of assets at $t-1$.

$R_{t}=\frac{P_{t-P_{t-1}}}{P_{t-1}}$

for each moment $t$, it is the rate of return at $t$ $1<t<T$ [6].

Suppose that the expectation of return $(R)$ of an asset is expressed as $E[R]$ which is the expected level of profit in the future, then it can be referred to as:

$\mu=E[R]$

\section{B. Exchange rate risk}

The risk in investment analysis is the uncertainty of future earnings from investments [16]. Risk can be referred to as a loss opportunity. When assets have a greater likelihood of loss, assets can be considered as risky assets [19]. In measuring risk, one observation is that investors' views about risk are asymmetrical about the mean [7]. Currency risk, also called exchange rate risk, represents the level or potential investment that is likely to be affected by exchange rate movements [5].

$\operatorname{Var}(R)$ is called the standard deviation, and in the modern portfolio theory Markowitz is called investment risk or totality. The return variance $R$, expressed as $\operatorname{Var}(R)$ is defined [10] by

$\operatorname{Var}(R)=E\left[r-\mu^{2}\right]$

\section{Covariance}

Portfolio theory is used to measure these statistics to reduce portfolio risk, and is defined by

$$
\sigma_{i j}=E\left[\left(R i-\mu_{i}\right)\left(R_{j}-\mu_{j}\right)\right]
$$

\section{Return Portfolio}

The return of a portfolio is a weighted average of the return of each asset, so

$R_{p}=w_{1} R_{1}+w_{2 R_{2}}+\mathrm{L}+w_{n} R_{n}$

$=\sum_{j=1}^{n} w_{j} R_{j}$ 


$$
=\left(\begin{array}{llll}
w_{1} & w_{2} & \mathrm{~L} & w_{n}
\end{array}\right)\left(\begin{array}{c}
R_{1} \\
R_{2} \\
\mathrm{M} \\
R_{n}
\end{array}\right)
$$$$
=w^{\prime} R
$$

Where, $R$ is the transpose of $R^{\prime}$ and $\mathrm{w}$ is the vector of portfolio weights and $\sum_{i=1}^{n} w_{i}=1$ (The weight can be negative, which means investors can reduce security) [16].

If the expectation of portfolio return is $\mu_{p}=\left[R_{p}\right]$, then the weighted average of each return expectation is:

$$
\begin{aligned}
& E\left[R_{P}\right]=E\left[w_{1} R_{1}+w_{2} R_{2}+\mathrm{L}+w_{n} R_{n}\right] \\
& =w_{1} E\left[R_{1}\right]+w_{2} E\left[R_{2}\right]+\mathrm{L}+w_{n} E\left[R_{n}\right] \\
& =w_{1} \mu_{1}+w_{2} \mu_{2}+\mathrm{L}+w_{n} \mu_{n} \\
& =\sum_{i=1}^{n} w_{i} \mu_{i}
\end{aligned}
$$

\section{E. Portfolio Risk}

Portfolio risk is a return variant of assets (sequences) that form the portfolio. One risk gauge is a standard deviation that is the square root of the variance. Whatever size is used, portfolio risk does not only depend on the risk of every security included, but also on interdependence between securities, except for cash positions, which are assumed to have a risk of 0 [13].

$$
\sigma_{p}^{2}=\sum \sum w_{i} w_{j} \sigma_{i j}
$$

Furthermore, the covariance of all asset returns can be expressed in the form of a matrix and equation (8) becomes $\sigma_{p}^{2}=w^{\prime} \Sigma w$ where

$$
\Sigma=\left(\begin{array}{rrrrr}
\sigma_{1 n} & \mathrm{~L} & \mathrm{~L} & \mathrm{~L} & \sigma_{i n} \\
\mathrm{M} & \mathrm{O} & & & \mathrm{M} \\
\mathrm{M} & & \mathrm{O} & & \mathrm{M} \\
\mathrm{M} & & & \mathrm{O} & \mathrm{M} \\
\sigma_{n 1} & \mathrm{~L} & \mathrm{~L} & \mathrm{~L} & \sigma_{n n}
\end{array}\right), w=\left(\begin{array}{c}
w 1 \\
\mathrm{M} \\
\mathrm{M} \\
\mathrm{M} \\
w_{n}
\end{array}\right)
$$

$$
w^{\prime}=\left(\begin{array}{lllll}
w_{1} & \mathrm{~L} & \mathrm{~L} & \mathrm{~L} & w_{n}
\end{array}\right)
$$

\section{F. Criterion Kelly}

In gambling, Kelly's criterion is a formula used to determine the optimal size of the bet sequence. In particular, Kelly Jr (1956) [24] shows that investing a small portion of wealth equal to the possibility of winning each bet maximizes the expected level of wealth growth. Alternatively, this rule can be generated by maximizing the logarithms expected from relative returns. So, according to Kelly Jr (1956) we need to solve the following maximization problems [3]:

$$
\begin{aligned}
& \max _{w}=E\left[W^{\prime} \mu\right] \\
& \text { s.t } \quad w^{\prime} e=1 \\
& w^{\prime} \Sigma w=R^{*} \\
& w \geq 0,
\end{aligned}
$$

\section{RESULTS AND DISCUSSION}

This section discusses the results and discussion which include: data analysis, estimation of return variance from each exchange rate, parameter estimation using covariance methods, and Kelly optimization analysis.

\section{A. Analysis data}

The object of this study is the data of the foreign exchange rate closing price of the daily exchange rate from the period of January 1 to December 31, 2017, obtained through the website http://www.bi.go.id. The data used in this study are the closing prices of JYP (Japanese Yen), CHF (Swich Franc), CNY (China Yuan), GBP (British Pound) and USD (United States Dollar) exchange rates. Price data for each exchange rate are calculated using equation (3) which will then be used to analyse the next section.

\section{B. Modelling exchange rates returns}

The exchange rate return of the five currencies in this study is calculated using equation (3). Figure 1 shows a graphical analysis of five exchange rates. The five-exchange return chart in Figure 1 shows the fluctuations in the closing price of the daily exchange rate for the period of January 1 to December 31, 2017 which is indicated by the rise and fall of the exchange rate chart. The acquisition of each exchange rate return varies greatly, including those that obtain the highest exchange rate return is the British Pound currency (GBP) of 0.027382362 in the period of 3 July 2017 and the lowest exchange rate return also obtained by GBP of -0.021100563 on November 3, 2017 with their respective numbers - each exchange rate is Rp. 2,890,809.14, Rp. 3,292,991.26 Rp. 480,293.32, Rp 4,177,016.86 and an exchange rate of USD Rp. 3,241,745.00.

\section{Portfolios Modeling Mean-Variance}

Equations (8) and (9) are used to calculate the value of return and variance of the portfolio for each of the five foreign currencies, whose data is shown in Table 1: 


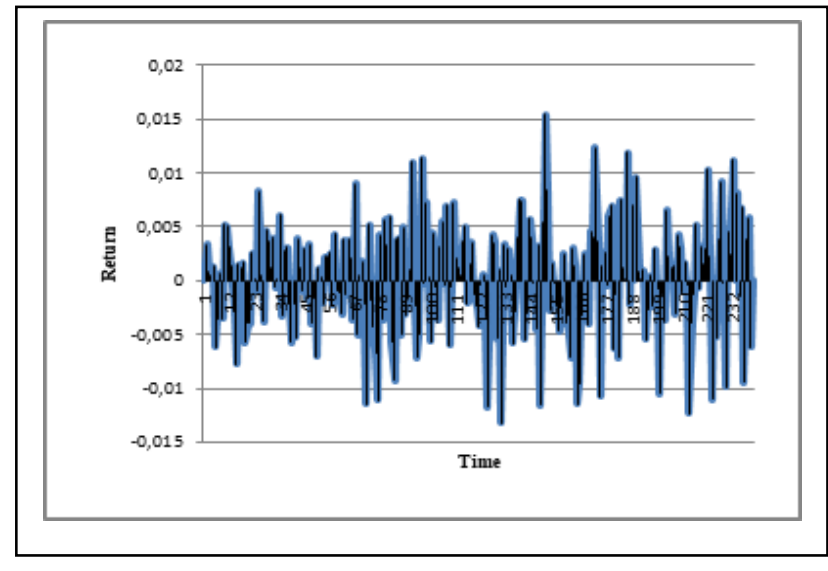

JYP

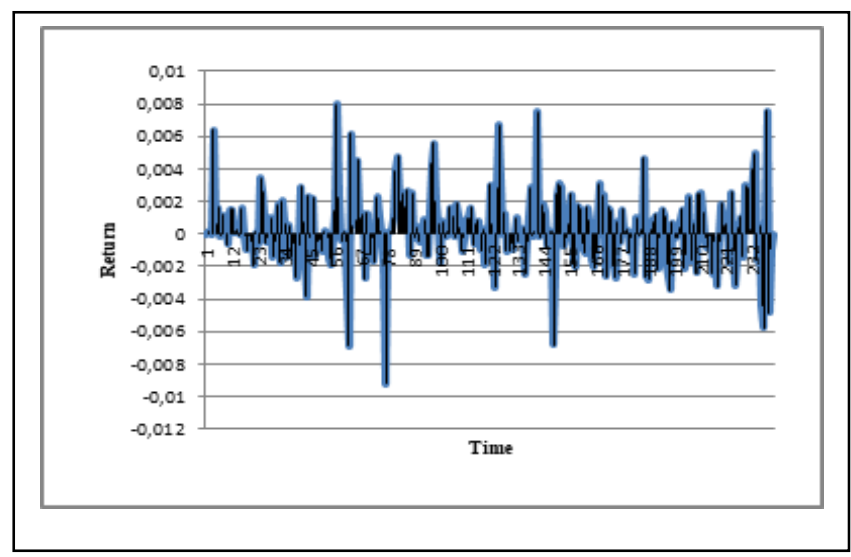

CNY

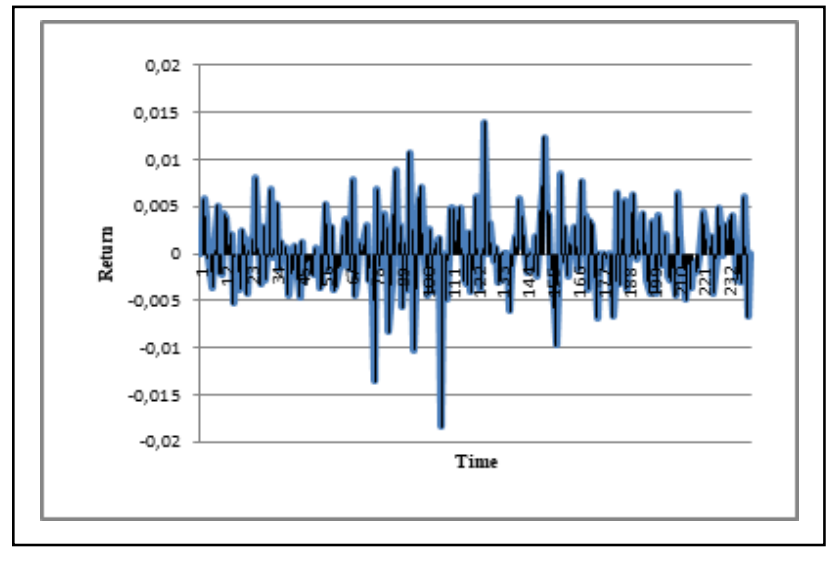

CHF

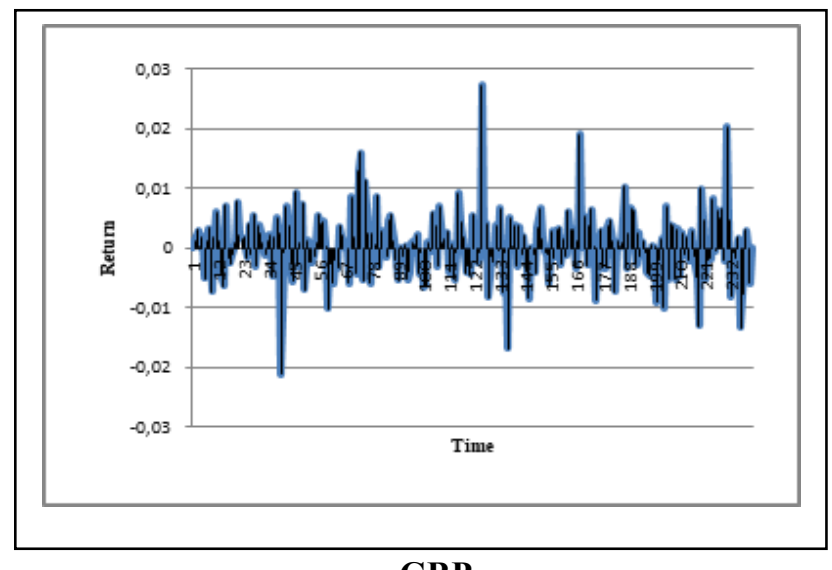

GBP

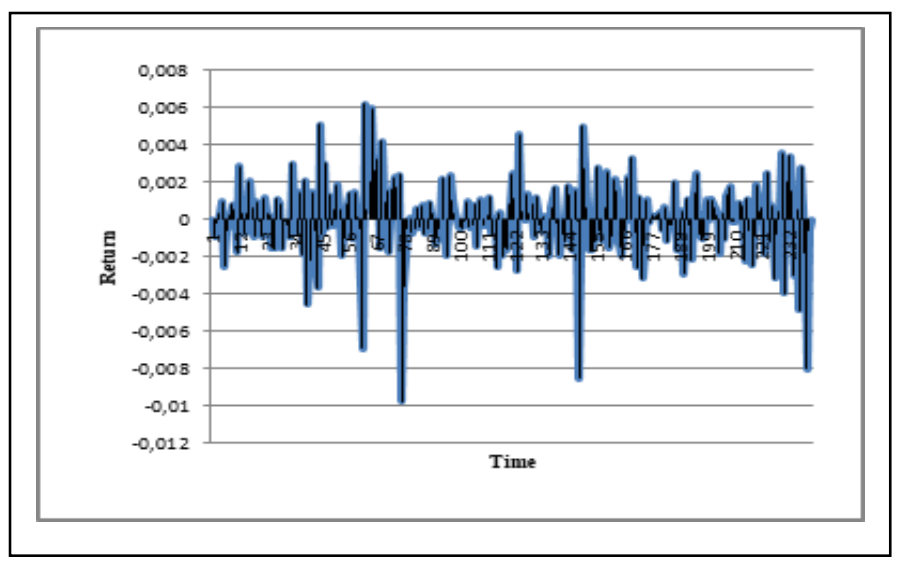

USD

Fig. 1. Five Foreign Currency Return Chart 


\begin{tabular}{|c|c|c|}
\hline \multirow{2}{*}{ Kurs } & Mean & Varians \\
\cline { 2 - 3 } & $\mu$ & $\sigma_{p}^{2}$ \\
\hline JYP & 0.000201712 & 0.00002526 \\
\hline CHF & 0.000203888 & 0.0000159329 \\
\hline CNY & 0.000277983 & 0.00000505123 \\
\hline GBP & 0.000403615 & 0.0000298072 \\
\hline USD & 0.0000215799 & 0.0000040727 \\
\hline
\end{tabular}

$W=\left[\begin{array}{c}w 1 \\ w 2 \\ w 3 \\ w 4 \\ w 5\end{array}\right]$ and $W^{\prime}=\left[\begin{array}{lllll}w 1 & w 2 & w 3 & w 4 & w 5\end{array}\right]$

By using equation $\sigma_{p}^{2}=w^{\prime} \Sigma w$ we gate the value $w$ for each currency with each proportion given in Table 2 .

Table 2 shows the acquisition of the proportion of portfolios provided by five foreign currencies, namely $9 \%$ for JYP, $-3 \%$ for CHF, $-54 \%$ for CNY, $35 \%$ for GBP and $112 \%$ for USD.

Calculation of portfolio proportions in Table 2 of several exchange rates gives a negative return value. Therefore, in analyzing a currency that provides a maximum return with a certain risk, the average value of a negative return is omitted to get the results of an optimal portfolio analysis of the five currencies. Results that provide optimal portfolios are shown in Table 3.

The optimal portfolio from the results of the analysis by Table 3 shows that those that provide maximum returns with certain risks are USD by $95 \%$ and JYP by $4 \%$.

\section{CONCLUSION}

The most common way to obtain an optimal portfolio is to use Markowitz mean-variance portfolio theory. General mean-variance theory does not address investment merging. However, a realistic theory with regard to investment is largely unable to help with reinvestment because accumulating wealth according to unimaginable investment merger is greater than other problems. So, to maximize the level of profit by building a portfolio by adding geometric averages of the calculated average. This is the purpose of Kelly Criterion. In this article, we analyze the portfolio of Variable Mean at several levels using Kelly Criteria with satisfying results. The results of the portfolio optimization calculation analysis, which is optimally achieved when the composition of the proportion of portfolio investment in JYP, CHF, CNY, GBP and USD currencies are: 0.3190, 0.2995, $0.1463,0.1600$ and 0.0753 . The composition of portfolio proportions will thus produce a portfolio with an average value of 0.0000215799 and the risk value is measured as a variance of 0.0000040727 . So that of the five currencies that are invested in the USD currency, the proportion of the portfolio obtained will provide a maximum return of $95 \%$.

\section{ACKNOWLEDGMENT}

Our thanks go to the Chancellor and Dean of the Faculty of Mathematics and Natural Sciences, Universitas Padjadjaran, especially for Lecturers who have helped and guided me in the preparation of this journal, namely Mr. Dr. Sukono and Mr. Dr. Endang Rusyaman who aims to improve research activities and publications to students in the Universitas Padjadjaran. 
Table 2. Process of Mean-Variance Portfolio Optimization

\begin{tabular}{|c|c|c|c|c|}
\hline & $\mu$ & $\sigma_{p}^{2}$ & $w^{\prime} e$ & \multirow{2}{*}{$w^{\prime} \Sigma w$} \\
\cline { 1 - 4 } Weight Portfolio & mean & variance & sum & \\
\hline 0.319 & 0.00020171 & 0.00002526 & 1 & 0.092299165 \\
\hline 0.2995 & 0.00020309 & $1.59329 \mathrm{E}-05$ & 1 & -0.02844074 \\
\hline 0.1463 & 0.00027798 & 0.000005051 & 1 & -0.54137968 \\
\hline 0.16 & 0.00040365 & 0.00002981 & 1 & 0.354901649 \\
\hline 0.0753 & 0.00002158 & 0.000004073 & 1 & 1.122619608 \\
\hline
\end{tabular}

Table 3. Optimal portfolio

\begin{tabular}{|c|c|c|c|c|c|}
\hline \multirow{2}{*}{ Kurs } & $w$ & $\mu$ & $\sigma_{p}^{2}$ & $w^{\prime} e$ & \multirow{2}{*}{$w^{\prime} \Sigma w$} \\
\cline { 2 - 5 } & $\begin{array}{c}\text { Weight } \\
\text { Portfolio }\end{array}$ & Mean & variance & sum & \\
\hline JYP & 0.319 & 0.00020171 & 0.00002526 & 1 & 0.045673703 \\
\hline USD & 0.0753 & 0.00002158 & 0.000004073 & 1 & 0.954326297 \\
\hline
\end{tabular}

\section{REFERENCES}

1. F. Abid F, L. M. Leung, M. Miroua and K. Wong. "International diversification versus domestic diversification: Mean-variance portfolio optimization and stochastic dominance approaches." Journal of Risk and Financial Management, vol 2, pp. 45-66, 2014.

2. F. Aliu, D. Pavelkova and B. Dehning. "Portfolio risk-return analysis The case of the automotive industry in the Czech Republic," Journal of International Studies, vol 10, pp 72-83, 2017.

3. G. Bottazzi and C. Santi. Relative performance of mean-variance, Kelly and universal portfolios in the equity market, 2017.

4. E. Dziwok. "Asset allocation strategyin investment portfolio Construction - A comparative analysis," Journal of Economics and Management, vol 14, pp. 124-132, 2014.

5. O. V. Fiador and J. F. Asare. "Cross-border investments, currency risks and portfolio returns: The case of Epack - Ghana," International Business Research, vol 6, pp. 137-144, 2013.

6. T. Florin D, Florin, B. Petre, F. Pavel and C. Sornia. "Practical aspects of portfolio selection and optimisation on the capital market." Economic Research-Ekonomska Istrazivanja, vol 30, pp. 14-30, 2017.

7. P. S. N. Gambra and T. A." Pirvu. Risk measures and portfolio optimization". Journal of Risk and Financial Management. vol 7, pp. 113-129, 2014

8. F. Garciaa, J. Alexander and J. Oliver. "Mean-variance investment strategy applied in emerging financial markets: Evidence from the Colombian stock market." Intellectual Economic. vol 9, pp. 22-29, 2015.

9. G. K. Gumus. "The relationship between foreign investment and macroeconommic indicators: Evidence from Turkey." European Scientific Journal, vol 11, pp. 388-399, 2015.

10. R. Jagannathan and T. Ma. "Risk reduction in large portfolios: A role for portfolio weight constraint," Journal of Finance, vol 58, pp. 1651-1683, 2003.

11. T. B. B. Maria, M. S. Joan and A. T. R. Maria. "Analysing assets' performance inside a portfolio: From crossed beta to the net risk premium ratio," Cogent Economics \& Finance, vol. 5, art.no. 1270251, 2017.

12. M. H. Maurizio, M. Elitza and S. Livio. The real exchange rate and economic growth: Revisiting the case using external instruments, Journal of International Money and Finance, vol 73, pp. 386-398, 2017
13. M. Lambovska and Jr. A. Marchev. Investment Portfolio Evaluation by Fuzzy Approach. Journal of Competitiveness, vol. 3, pp. 13-26, 2011.

14. K. Micheal. "Markowitz and Kelly portfolio theories in iPython", Computing in the Financial World, vol 35, pp. 917-926, 2016.

15. J. Neely and Christopher. "An analysis of recent studies of the effect of foreign exchange intervention," Federal Reserve Bank of St. Louis Review, vol 87, pp. 685-717, 2005.

16. I. Omisore, M. Yusuf and N. Christopher, "The modern portfolio theory as an investment decision tool," Journal of Accounting and Taxation, vol 4, pp. 19-28, 2012.

17. M. R. Safarzadeh, F. I. Nazarian and A. K. C. "Molina. Efficiency of currency asset classes." International Journal of Economics and Financial.vol 3, pp. 544-558, 2013.

18. S. Senthilnathan. "Risk, return and portfolio theory - A contextual note." International Journal of Science and Research, vol. 5, pp. 705-715, 2016

19. S. Senthilnathan. "Risk, return and portfolio theory-A contextual note", International Journal of Science and Research, vol 5, p 2319-7064, 2016.

20. A. Simsek, "Speculation and risk sharing with new financial. Assets", The Quarterly Journal of Economics, vol 128, pp. 1365-1396, 2013.

21. K. Spyros, N. D. Chandrinos and Lagaros. "Construction of currency portfolios by mean of an optimized investment strategy." Operation Research Perspectives. vol 5,pp. 32-44, 2018.

22. R. Vince, "Optimal f and the Kelly Criterion." IFTA Journal, vol. 11 pp. 21-28, 2011.

23. P. Zachariah. "The Kelly criterion in portfolio optimization: a decoupled problem", Journal of Investement Strategie, vol 7, p 53-76, 2018.

24. S. A. Zenios and W. T. Ziemba, Handbook of Asset and Liability Management: Applications and case studies (Vol. 2). Elsevier, 2007. 